\title{
An Employee-Focused Human Resource Management Perspective for the Management of Global Virtual Teams
}

\begin{abstract}
The number of global virtual teams (GVTs) has increased in recent years due to globalization of business, improved information and communication technology, and higher innovation needs. Practitioners expect GVTs to be creative, innovative, and high-performing. However, GVT members suffer from interpersonal problems, stress, and misunderstandings based on cultural differences. It is therefore important that the human resource management (HRM) function intervenes in the functioning of GVTs. HRM and GVT research has mostly focused on instrumental practices to improve performance. Globalization and the dynamic business environment require international organizations to adopt new HRM perspectives. To advance research on GVTs and HRM, we draw on the job demands-resources model and research on quality of work life to introduce an employee-focused HRM perspective for the management of GVTs. This new perspective focuses explicitly on improving employee wellbeing. We develop a novel theoretical framework that provides HR practitioners and leaders with several employee-focused management tools such as flexible work practices, international training and development opportunities, and fair pay and procedures. These tools are likely to help GVT members to cope with job demands and to improve their well-being, and are particularly useful for GVTs due to their interpersonal problems, stressful environment, and cultural differences.
\end{abstract}

Keywords: global virtual teams, employee-focused human resource management, international human resource management, employee well-being, cultural diversity, job demands-resources model 


\section{Introduction}

As organizations globalize, they are operating beyond national boundaries, creating new business opportunities but also new challenges with regard to the management of employees such as the management of global virtual teams (GVTs) (Gibson \& Gibbs, 2006). GVTs are composed of members with different nationalities 'in two or more countries who communicate primarily using information and communication technology’ (Martins \& Schilpzand, 2011: 1). Due to globalization of business, higher innovation needs, and improved information and communication technology, the number of GVTs has strongly increased in the past decade (Gilson, Maynard, Jones Young, Vartiainen, \& Hakonen, 2015). Management consultants and practitioners associate a high potential with GVTs in terms of greater innovation and performance. However, just bringing experts 'together virtually provides no guarantee that they will be able to work effectively and innovate' (Gibson \& Gibbs, 2006: 452-453). GVTs often suffer from cultural differences, interpersonal problems, miscommunication, and a stressful environment that prevent these teams from benefiting from their cultural diversity (Furoma, 2009). To reduce these demands, there are many challenges for human resource management (HRM) and leaders (Zander \& Butler, 2010; Zander, Mockaitis, \& Butler, 2012).

Unfortunately, human resource (HR) managers often lack experience with GVTs, requiring academic research to provide recommendations and to develop best practices for the management of GVTs. By drawing on the job demands-resources (JDR) model (Bakker \& Demerouti, 2007; Demerouti, Bakker, \& Leiter, 2001) and research on the quality of work life (Grote \& Guest, 2016; Walton, 1976), we develop a novel theoretical framework that advances the integration of the literatures on GVTs and HRM, providing several theoretical and practical contributions. First, we expand GVT research by taking a new well-being-based perspective. This new perspective is important for GVTs, because GVT members often suffer from interpersonal 
conflict (Daim et al., 2012), stress (Nurmi, 2011), and uncertainty (Crisp \& Jarvenpaa, 2013). We present management tools, derived from international HRM (IHRM) practices, to improve the well-being of GVT members. Surprisingly, GVT research mostly applied an instrumental perspective to investigate GVTs and focused on task performance without considering employee well-being (Gilson et al., 2015; Martins \& Schilpzand, 2011).

Second, we expand IHRM research by introducing a new employee-focused HRM perspective based on the JDR model (Demerouti et al., 2001) and research about quality of work life (Grote \& Guest, 2016; Walton, 1976). Previous HRM research has mostly focused on the effectiveness of high performance work systems and practices, whose main goal is to improve organizational performance (Guest, 2011). However, the performance-focused HRM perspective neglects employee well-being (Guest, 2011). The role of HRM is changing due to globalization, the dynamic business environment, and social changes (Nishii \& Özbilgin, 2007). Organizations have to consider new HRM perspectives and approaches in order to adapt to this new environment (Guest \& Woodrow, 2012). It must be important for international organizations with GVTs to align their IHRM strategies with their team-based structures (Gibbs \& Boyraz, 2015). Research on GVTs has focused on the situation and interactions inside teams (Gilson et al., 2015), neglecting the role of HRM. Our new HRM perspective takes explicitly into account employee well-being, and is particularly valuable for the management of GVTs due to their higher susceptibility to interpersonal problems, cultural differences, and stressful interactions that result from working with employees from different countries (Nurmi, 2011).

Finally, we expand research on the JDR model by applying it to the context of GVTs, which represents a new research context. This model emerged as popular theoretical framework to investigate stress and employee well-being in the workplace (Bakker \& Demerouti, 2007; Demerouti et al., 2001). We adapt the theory of the JDR model to GVTs, and therefore provide 
information whether the model applies to this specific context. According to this model, employee well-being decreases when an imbalance between job demands and job resources exist. The JDR model represents an appropriate theoretical foundation for our framework, as it explains crucial factors of well-being. The model is therefore useful to introduce an employee-focused HRM perspective for GVTs. We argue that GVTs require HRM support to cope with job demands that result from their cultural diversity, virtuality, and geographic dispersion.

\section{Literature Review}

\section{Review of Research on Global Virtual Teams}

GVTs emerged as a new form of organizing work. Previous research has found that, compared to traditional teams, GVTs are often less cohesive (Polzer, Crisp, Jarvenpaa, \& Kim, 2006), and that their members have less trust in each other (Gibson \& Manuel, 2003; Newell, David, \& Chand, 2007). In addition, GVTs often have difficulties to communicate and coordinate effectively (Hinds \& Weisband, 2003). These negative dynamics are caused by the specific characteristics of GVTs. Previous research has indicated that, compared to traditional teams, GVTs tend to be characterized to a higher extent by nationality and cultural diversity, geographic dispersion, electronic dependence, and structural dynamism (frequent change of team members) (Gibson \& Gibbs, 2006). Previous research has also shown that these teams often lack clear hierarchy and structure (Lipnack, \& Stamps, 1999). Due to geographic dispersion, face-to-face interactions are often lacking. To work together, team members have to communicate electronically (Martins \& Schilpzand, 2011).

Most GVT research has focused on the situation and employee interactions inside GVTs (Martins \& Schilpzand, 2011). This research has identified several key factors of successful GVTs at the individual and team level. At the individual level, successful GVTs often had team members with high cultural intelligence and open-minded attitudes (Blackburn, Furst, \& Rosen, 
2003; Erez et al., 2013) as well as members with high technological expertise that allowed them to use computer-mediated communication and collaboration technologies that enable coordination and cooperation (Ramalingam \& Mahalingam, 2011). At the team level, researchers identified knowledge sharing (Hinds \& Weisband, 2003) and development of trust (Gibson \& Manuel, 2003) as pre-conditions for effective GVT team functioning. Although this research provides useful managerial implications, it is also important to integrate external factors to better understand and manage GVTs (Cohen \& Gibson, 2003). Recent research has started to consider the role of leaders for the functioning of GVTs. This research illustrates that the role of leaders is more challenging and complex than in traditional work settings. For example, leaders should be culturally intelligent, act as boundary spanners, and exercise people-oriented leadership (Zander et al., 2012). Building on this research, we aim to integrate the HRM context in order provide IHRM tools for an effective management of GVTs.

\section{Review of Research on International Human Resource Management}

As a result of globalization, organizations realized that domestic HRM systems had to be adapted and expanded to meet the needs of international organizations and of a culturally diverse workforce (Dowling, Festing, \& Engle, 2008). An international orientation was therefore integrated into HRM practice and research. This means IHRM still reflects traditional HRM tasks and areas such as recruitment, selection, job design/description, training and development, performance appraisal, and reward system. The difference is that an international component has been added to these factors, requiring HRM to take broader perspectives and to exercise more complex HR activities (Dowling et al., 2008). IHRM research provided interesting research findings and useful recommendations. For example, it investigated and even helped to develop international recruitment and selection systems (Reiche \& Harzing, 2011). Crucial selection criteria such as cultural intelligence or open-mindedness have been also identified for the 
recruitment of global team members and expatriates (Erez et al., 2013). IHRM research also investigated cross-cultural training in order to help employees to become more culturally sensitive and to help organizations to integrate cultural differences in their strategy and marketing campaigns (Okpara \& Kabongo, 2010). Research also suggests that HRM systems should be adapted depending on the country's cultural values (Taras, Kirkman, \& Steel, 2010). Such adaptation promises a performance improvement of $10-20 \%$ (Taras et al., 2010). Although IHRM research led to these important findings, it neglected to some extent employee well-being. The neglect of employee well-being can be considered not only a limitation of IHRM research but of HRM research in general (Greenwood \& de Cieri, 2007; Grote \& Guest, 2016; Guest \& Woodrow, 2012). HRM research has focused on developing practices or providing recommendations to improve employee productivity and performance (Guest, 2011). The main outcome that has been investigated was financial performance (Beer, Boselie, \& Brewster, 2015). In the past years, several new HRM perspectives have been developed such as an extended Harvard model (Beer, Spector, Lawrence, Quinn Mills, \& Walton, 1984), high performance work systems (Becker \& Huselid, 1998), high commitment HRM (Whitener, 2001), and high involvement HRM (Boxall \& Macky, 2009). These models can be considered as a starting point to integrate employee well-being as outcome of HRM (see also Brown, McHardy, McNabb, \& Taylor, 2011). However, these models do not focus explicitly on employee well-being. The Harvard model focuses on stakeholders, while high performance work systems focus on employee performance. High commitment HRM and high involvement HRM are also instrumental approaches, because they consider commitment and involvement as means to improve employee productivity (Guest, 2011). To integrate employee well-being more explicitly into IHRM research, we draw in this paper on research on quality of work life (Walton, 1976) and on the JDR model (Demerouti et al., 2001). More precisely, we explore the role of 
international HR practices in improving employee well-being in GVTs.

\section{Review of Research on the Job Demands-Resources Model}

Demerouti and colleagues (2001) developed the JDR model to analyze predictors and conditions of psychological well-being and stress in the work environment. This model therefore provides an appropriate theoretical foundation to investigate employee well-being in the context of GVTs. The model distinguishes between job demands and job resources. Job demands are psychological and organizational characteristics of one's job that cause psychological stress and consume cognitive resources. Examples of job demands are high workload, interpersonal conflict, and uncertainty. GVT members often suffer from these job demands, indicating the importance of applying the JDR model to the context of GVTs. Job demands function as stressors that trigger a health impairment process. As a consequence, employees suffer from stress, workfamily conflict, health problems, or even burn-out (Demerouti, Bakker, \& Leiter, 2014).

In contrast, job resources represent aspects of one's job that are useful to conduct one's tasks or to achieve one's objectives (Demerouti et al., 2001). Examples of job resources are job autonomy, career and development opportunities, and clear job descriptions. Job resources are beneficial for employee well-being, as they reduce job demands and the related consumption of cognitive resources (Demerouti et al., 2014). Job resources elicit positive motivational processes that increase employee well-being. This means job resources are able to buffer negative effects of job demands. Research has shown that job resources play a particularly important role for employee well-being when job demands are high (Molines, Sanséau, \& Adamovic, 2017). Taken together, the JDR model analyzes the interaction of job demands and job resources, and argues that an imbalance has dysfunctional effects on employee well-being and performance. The JDR model is a general model (Bakker \& Demerouti, 2007), which means the specific job demands and resources differ across occupations and contexts. To advance research on the JDR model, we 
apply it to the context of GVTs, representing a new research context.

\section{Theoretical Framework about Global Virtual Teams}

In line with the JDR model, we first identify job demands in GVTs. After that, we present and explain possible job resources in the context of GVTs. These job resources represent employee-focused management tools for HR practitioners. The lower part of our theoretical model represents the GVT level (Figure 1). The upper part of our model represents the IHRM level (Figure 1). Based on the JDR model, we argue that to prevent the emergence of job demands or to buffer their dysfunctional effects on employee well-being, it is important for the organization and managers to provide job resources to support GVTs. In the context of GVTs, we consider employee-focused HRM tools as crucial job resources. In the following, we explain the different elements, relationships, and propositions of the model.

\section{INSERT FIGURE 1 ABOUT HERE}

\section{Job Demands in GVTs}

Gibson and Gibbs (2006) identified cultural diversity, geographic dispersion, electronic dependence, and structural dynamism as main characteristics of GVTs. These characteristics are therefore the starting point of the theoretical framework (Figure 1). These characteristics often negatively influence GVT dynamics and cause several job demands (Martins \& Schilpzand, 2011). In the following, we explain the development and effects of job demands in GVTs. We distinguish between socio-emotional and team process-oriented job demands.

\section{Predictors and consequences of socio-emotional job demands in GVTs}

GVTs often suffer from interpersonal and process problems due to different work expectations, cultural differences, and languages (Kankanhalli, Tan, \& Wei, 2007). One of the common problems of GVTs is that they tend to experience interpersonal problems related to 
unfairness (Earley \& Gibson 2002) and dysfunctional types of conflict (Daim et al., 2012). For example, the European company Airbus has experienced these problems with their GVTs. Airbus has many French-German teams. French and German employees often have different cultural values (Hofstede, Hofstede, \& Minkov, 2010), especially regarding the cultural value dimension polychronicity versus monochronicity (Bluedorn, Kaufman, \& Lane, 1992). French employees tend to be polychronic. This means they often prefer multi-tasking, flexibility, and spontaneity in the workplace. In contrast, German employees tend to be monochronic. This means they often prefer clear work schedules and plans. Interpersonal conflict and coordination problems emerged in the teams when Airbus experienced technical difficulties with regard to the development of the aircraft A380 (Le Monde, 2008). German employees criticized French teammates to be unorganized and chaotic (Oncomprendrhin, 2011). On the other hand, French employees criticized German teammates to lack creativity and flexibility. These negative dynamics were strengthened by pay differences between German and French employees (La Dépêche, 2008). The interpersonal problems created a very stressful work environment and had detrimental effects for the well-being of employees, and Airbus suffered from financial losses, because it had to delay the introduction of the aircraft A-380 (l'express, 2010). This also had negative effects on its reputation. Using terminology from the JDR model, the interpersonal conflict and problems that the teams experienced are called job demands. As a consequence of these job demands, GVT members often experience stress and job strain (Bakker \& Demerouti, 2007). The management of these job demands is very challenging for HRM and team leadership (Zander \& Butler, 2010).

To explain the emergence of job demands in GVTs, we draw on social identity theory (Hogg \& Terry, 2000), which argues that members categorize teammates in in- and out-groups based on salient diversity attributes. This categorization process helps individuals to define their self-concept based on group membership (Hogg \& Terry, 2000). As many different attributes 
(nationality, age, gender, etc.) exist to categorize teammates, it is crucial to understand on which attributes the categorization is based. Usually, the categorization is based on attributes that are salient in the team and organization and that are personally important for the individual (Earley \& Gibson, 2002). Diversity is socially constructed and lies in the eye of the beholder.

In the context of GVTs, nationality, team membership (full-time versus part-time members), and geographic location are likely to be salient diversity attributes. Continuing our example with the French-German teams of Airbus, nationality was the salient attribute in the teams. Teammates with the same nationality were therefore likely to be categorized as in-group. In-group members may experience a preferred interpersonal treatment and benefit from higher social standing (Stone \& Stone-Romero, 2005). Teammates with a different nationality were likely to be categorized as out-group and to suffer from social exclusion. Prejudices and discriminations may arise from these categorization processes, leading to intense and numerous conflicts in GVTs (Daim et al., 2012). Decisions, relationships, and treatment inside GVTs could be based on surface characteristics like nationality, instead of useful work evaluation criteria like job attitudes, task-relevant knowledge, and job performance. A serious disruption of the GVT functioning could be the consequence (Au \& Marks, 2012). It is likely that the potential of GVTs cannot be exploited when members suffer from job demands such as interpersonal conflict, disrespect, and impoliteness. As a consequence, members' well-being will be reduced.

Proposition 1a: GVT characteristics reduce GVT members' well-being through socioemotional job demands (i.e., increased conflict and perceptions of unfairness).

\section{Predictors and consequences of team process-oriented job demands in GVTs}

GVT members often have different perspectives and ways of thinking (Earley \& Gibson, 2002). Practitioners, researchers, and consultants therefore associate with GVTs a high potential related to learning, creativity, and innovation (Martins \& Shalley, 2011). However, due to the 
specific characteristics of GVTs and the related categorization processes, the potential of GVTs is often not exploited (Martins \& Schilpzand, 2011). Instead, GVT members experience additional job demands such as reduced decision-making and problem-solving quality (Martins \& Schilpzand, 2011), reduced knowledge and information exchanges (Hinds \& Weisband, 2003), and reduced learning (Cogburn, Zhang, \& Khothule, 2002). These team processes are the most important team processes for high-performing GVTs to transfer their cultural diversity into performance (Collins, Chou, Warner, \& Rowley, 2015). These processes are essential for coordinating and organizing teamwork, and they represent one important pre-condition for team performance and innovation (Marks, Mathieu, \& Zaccaro, 2001). If these team processes are not effective, they are perceived as job demands by GVT members. These job demands are likely to have detrimental effects on the well-being of GVT members.

Proposition 1b: GVT characteristics reduce GVT members' well-being through team process-oriented job demands (i.e., reduced knowledge sharing and reduced team learning).

\section{Job Resources for GVTs}

The potential of GVTs is often not exploited and GVT members tend to suffer from stress due to job demands that result from GVT characteristics and related social categorization processes. Based on the JDR model (Demerouti et al., 2001), we argue that international HR managers should intervene in the GVT functioning in order to provide job resources that reduce job demands in GVTs. Complementary to the situation inside the team, we therefore consider the role of IHRM. To illustrate job resources in the context of GVTs, we draw on research on quality of work life (Walton, 1976). Walton argues that eight factors are crucial to improve employee well-being: 1) development of human capacities, 2) growth and security, 3) social integration, 4) social relevance of work, 5) rights and representation, 6) adequate and fair compensation, 7) consideration of total life space, and 8) safe and healthy working environment. 
Integrating the context of GVTs and based on conceptual similarity, we grouped these well-being conditions into four overall categories: 1) Development of international skills and careers (includes the well-being conditions 'development of human capacities' and 'growth and security'), 2) international corporate culture (includes 'social integration' and 'social relevance of work'), 3) IHRM policies (includes 'rights and representation' and 'adequate and fair compensation'), and 4) work-life balance (includes 'consideration of total life space' and 'safe and healthy working environment') (Figure 2). These four categories represent the basis of our employee-focused HRM perspective for GVTs. Each category includes several IHRM tools that focus on employee well-being and that promise to help GVT members to avoid or reduce job demands (Figure 2). Examples of employee-focused HRM tools in the first category are international-oriented training, opportunity to use skills, and international career development. In the second category, we included teambuilding and organizational support. Examples that we discuss in the third category are international reward system, rights and representation, and job description. Finally, in the fourth category, we discuss flexible work practices and scheduling, team structure, and task-technology fit. Generally speaking, we expect the employee-focused HRM tools to function as moderators of the relationships that are observed at the GVT level, and that we described in the Propositions 1a and 1b. The HRM tools should moderate not only one specific relationship but rather the full set of indirect relationships that can be described as health impairment processes. The effective application of these job resources should weaken health impairment processes, helping GVT members to cope effectively with job demands and to improve their well-being.

INSERT FIGURE 2 ABOUT HERE

\section{Development of International Skills and Careers}




\section{International-oriented Human Resource Training}

An important employee-focused HRM tool to develop and grow human capacities is HR training. Due to the specific context of GVTs, it is necessary to adapt HR training to the international environment. This means the training should focus on cultural intelligence (Erez et al., 2013), cultural values (Hofstede et al., 2010), or global mindset (Gupta \& Govindarajan, 2002). Helping GVT members to develop these global interpersonal skills will allow them to handle cultural diversity more effectively. This means international-oriented training is likely to function as a job resource and to reduce job demands that result from cultural diversity. This is likely to create a better team atmosphere that is characterized by trust, cohesion, and solidarity instead of unfairness and conflict. As final outcome, we are likely to observe an increase in employee well-being and health. At the same time, GVT members with global interpersonal skills may recognize positive aspects of cultural diversity. These members may consider cultural diversity a source of learning and personal development. As a result, the dysfunctional effects of cultural diversity on team process-based job demands might be reversed into beneficial effects.

HRM should further offer technology training to GVTs to help members effectively use all available information and communication technologies. GVT members often must communicate most of the time electronically rather than face-to-face (Martins \& Schilpzand, 2011). However, to communicate, coordinate, and cooperate effectively with geographically distant teammates, an adequate level of technological expertise is required (Ramalingam \& Mahalingam, 2011). Effective technology training can function as a job resource that helps GVTs to improve their ability to deal with job demands that result from electronic dependence and geographic dispersion in GVTs. GVT members who rely on computer-mediated communication to communicate with each other often feel isolated and uncertain about team member roles and what is expected of them, leading to greater misunderstandings (Kurland \& Bailey, 1999), in 
addition to less shared understanding of others in the team (Hinds \& Weisband, 2003). However, when computer-mediated communication is used effectively, GVT members can overcome these challenges. Adequate technological expertise for computer-mediated communication and advanced collaboration tools may bring GVT members to consider their electronic dependence not as a liability but as an opportunity to better organize and coordinate their work (Montoya, Massey, \& Lockwood, 2011).

GVT members often change the team, and the membership of most members is not stable. To weaken the negative effects of structural dynamism on employee well-being, it is important that the IHRM function provides HR training related to teamwork and conflict management. Such training could include perspective taking (Deutsch, 2002) or emotional intelligence (Goleman, 2009).

Leading GVTs is challenging due to the specific characteristics of these teams (Zander \& Butler, 2010; Zander et al., 2012). Therefore, IHRM should invest in leadership development programs that help leaders to develop capabilities for leading GVTs. Effective leadership training should include all the above described training (related to cultural intelligence, technology, and interpersonal skills) but also specific leadership capabilities that relate to more formal management skills such as planning, coordination, and goal setting. Engaged, committed, and well-organized leaders are likely to provide support to GVT members. This is likely to help these members to cope with stressful job demands in GVTs. Effective leaders can be even considered a job resource. Put differently, engaged and committed leaders may function as a source of positive energy for GVT members (Tims, Bakker, \& Xanthopoulou, 2011). Leaders are particularly important for team members working in stressful environments (Schaufeli, 2015). A positive and energized leader is likely to spread positive emotions across the team (Sy, Cote, \& Saavedra, 2005), creating a positive work environment and helping the team to cope with job demands. 


\section{Opportunity to use Skills}

Besides offering technology training, it is necessary that HRM establishes the right environment that provides GVT members with opportunities to use their technological skills and competencies in an effective way. In the past decade, the area of HRM has been expanded by a technology component to integrate recent developments in information and communication technology (Stone \& Dulebohn, 2013). In the context of GVTs, technology environment includes computer availability, basic technical tools, and email access but also more advanced technology such as sharing documents through cloud software (e.g., Dropbox, Google Drive, Sharepoint, and Figshare), simultaneous working on several documents (e.g., Google docs and Scribblar), meeting software (e.g., Skype, Zoom, Gotomeeting, and Google Hangouts), collaboration software (e.g., Blackboard Collaborate, Huddle, DeskAway, and AffinityLive), project management software (e.g., Microsoft project Atlassian, Podio, and Basecamp), and corporate social networking (e.g., Yammer, Tibbr, SocialCast, and Jive). HRM should collaborate closely with GVTs to provide required technology and software. The provision of required technology or software will function as a job resource and will help to ameliorate negative effects of electronic dependence in GVTs. The appropriate provision of technology will allow all members to contribute with their unique knowledge and perspectives to the success of the team.

To use effectively the diverse knowledge and skills of GVTs, HRM should provide the right technology to GVT members to effectively share information and knowledge with each other. This would help GVTs to reduce team process-oriented job demands that result from GVT characteristics. Cultural diversity, electronic dependence, and geographic dispersion will also cause fewer misunderstandings and interpersonal problems. In addition, negative effects on the team atmosphere are likely to be weakened by using meeting software and corporate social networking. These tools will help GVT members to better to know each other, increasing even 
trust and cohesion. Corporate social networking will also help GVTs to develop an external network across the organization, helping these teams to get required external support for their complex tasks and projects despite their geographic dispersion.

\section{International Career Development}

To further develop and grow human capacities in GVTs, it is important that HRM offers possibilities to GVT members to develop international careers. International career development programs can include international work assignments, international networking opportunities, and recognizing GVT-work as criteria for promotion (Stahl \& Cerdin, 2004; Stahl, Miller, \& Tung, 2002). All these factors are useful to develop talents and knowledge (Dickmann \& Doherty, 2008), and are likely to function as job resources for GVT members. As already explained, crucial skills that GVT members should have are related to cultural intelligence and global mindset. Research has indicated that international work experience helps employees to acquire these global skills and competencies (Biemann \& Andresen, 2010; Stahl \& Cerdin, 2004). HRM should therefore offer international work assignments to their employees, helping employees to become more culturally sensitive and to grow as persons. This will help GVT members to cope with dysfunctional effects of cultural diversity and geographic dispersion on job demands and well-being.

Another benefit of international work assignments is the possibility to develop an international network (Dickmann \& Doherty, 2008; Dickmann \& Harris, 2005). This is crucial for GVT members, as GVTs often make decisions and develop strategies that need to be implemented in different countries. A successful implementation requires the endorsement of the host country's workforce. Therefore, it is important that GVT members have an international network across countries in order to get required support for their decisions. An international network facilitates the work and coordination of GVTs. GVT members will have more time and 
cognitive resources. As a result, they have more energy to deal with job demands in their GVTs. An international network is also helpful for the careers of GVT members, increasing their work motivation and work engagement.

Another important pre-condition for work engagement in GVTs is likely to be members' perceptions about the contribution of their work in the GVT to their overall career (Dickmann \& Harris, 2005). Does working in a GVT benefit one's career or does it interfere with one's career development? Are employees still 'visible' for promotions if they work in a GVT? HRM has to communicate to members that their work in their GVT is highly valued. It should be part of their performance evaluation. HRM could even consider working in a GVT as a positive criterion with regard to promotion, motivating employees to engage in their team and to manage better their interpersonal differences.

Proposition 2: The development of international skills and careers is likely to function as a job resource for GVTs that weakens dysfunctional effects of GVT characteristics on job demands and employee well-being.

\section{International Corporate Culture}

In the category 'international corporate culture', we group employee-focused HRM tools that relate to social integration and social relevance of work. Both factors have been identified by research on social integration (Bunderson \& Boumgarden, 2010) and organizational climate (Schneider, 1990) as important factors to understand the functioning of high-performing teams.

\section{Teambuilding}

To create social integration in GVTs, IHRM has to assist GVTs to develop into cohesive teams, in which cultural differences and geographic dispersion are not considered liabilities but sources for learning and development. The specific context of GVTs makes teambuilding more complex and complicated. IHRM has to encourage teams to build identification and cohesion in 
an international environment. In addition, it has to pay attention how it treats GVT members and how GVT members treat each other. Finally, IHRM has to provide the right technology to GVTs in order to help members to bridge their geographic dispersion and cultural diversity.

Previous research has shown that an effective way to build cohesive GVTs is to allow members to meet face-to-face before they start their GVT work (Newell et al., 2007). This faceto-face meeting requires some financial investment, as the members often work in different countries. However, the benefits often outweigh the costs, as face-to-face meetings allow team members to establish swift trust and familiarize themselves with each other. These first interactions reduce the likelihood that cultural diversity and geographic dispersion will become the basis for social categorization processes and stereotyping. In addition, electronic dependence is less likely to be a liability that causes job demands, because members who have met face-toface are less likely to interpret negative intentions of teammates in electronic communication. To increase identification and trust, IHRM should also try to organize face-to-face meetings in later stages of the team existence.

Another way to reduce the impact of job demands in GVTs and to create team cohesion is to focus on fairness. Although the implementation of fairness norms can differ across cultures, it is noteworthy that fairness is a universal need and desired in all cultures ( $\mathrm{Li} \&$ Cropanzano, 2009). Put simply, everyone wants to be fairly treated. Research has shown that perceptions of fairness are likely to improve team functioning, increasing team performance and satisfaction (Whitman, Carpenter, Horner, \& Bernerth, 2012). Accordingly, the implementation of fairness standards in GVTs can help these teams to reduce their job demands and to focus on their actual tasks and goals, increasing employee well-being and performance. A possibility could be to encourage GVTs to establish a team charter that regulates interpersonal norms and interactions. This will help GVT members to treat each other with fairness, respect, and politeness. As a result, 
negative social categorization effects on well-being will be buffered. Members are likely to neglect interpersonal and cultural differences, helping the team to establish a positive team atmosphere.

Not only should IHRM help GVTs that their members treat each other with fairness and respect, IHRM itself should also treat GVT members in a fair and equal way. It is important that all members are treated in the same way and that certain members from a specific country or department are not preferred. As a result, GVT characteristics should have less dysfunctional effects on job demands and employee well-being. A different treatment of GVT members by HRM and general management is likely to elicit perceptions of injustice. Treating GVT members in a different way is likely to make cultural diversity, geographic dispersion, and structural dynamism more salient. This means in- and out-group distinctions will be emphasized and social categorization processes will be strengthened, increasing negative effects of GVT characteristics on the existing job demands and well-being. If GVT members from specific countries are preferred, it is likely that the disadvantaged and culturally different members are more motivated to engage in conflict and to withhold important information. A bad work atmosphere and reduced knowledge exchange are the result, further reducing employee well-being. In addition, perceptions of inequality may bring disadvantaged GVT members to believe that they are unfairly treated because of their different cultural background.

Due to the context of GVTs, an effective technology infrastructure may assist GVTs to become a real team and to avoid negative dynamics inside the team (Martins \& Schilpzand, 2011). Technology tools provide GVT members with an opportunity to cooperate effectively with teammates and to develop mutual understanding. As GVTs are often composed of members who have never worked together and who do not know each other, it is likely that shared mental models are difficult to develop. Shared mental models are important in teams for effective 
coordination and cooperation, because they indicate whether team members know the skills and knowledge of their teammates (Hinds \& Weisband, 2003). By knowing the background and job specialization of teammates, a more effective cooperation and coordination can develop (Hinds \& Weisband, 2003). It has been argued that individuals need to be aware of what others are doing and of each team member's expertise in order to properly coordinate with them, leading to effective cooperation and team performance (Rico, Sánchez-Manzanares, Gil, \& Gibson, 2008).

\section{Organizational Support}

GVTs also require support and help of employees who are not members of GVTs. Members of GVTs are often also members of a traditional team in their home department and country (Maynard et al., 2012). Cooperative and benevolent coworkers are one key factor for employees to handle their multiple team memberships (Bertolotti, Mattarelli, Vignoli, \& Macrì, 2015). It is therefore important that HRM communicates to members of traditional teams that some persons are also members of a GVT. The membership to a GVT includes additional tasks, duties, and responsibilities. Consequently, GVT members have less time and energy to engage in cooperation with their traditional team, requiring sympathetic teammates. It is very challenging for most employees to manage multiple team memberships. A supportive organizational culture is therefore a key factor for the success of GVTs. By experiencing the encouragement of their peers, GVT members will feel capable to fully engage in their GVT, contributing effectively to reduce job demands, to improve teamwork, and to cooperate with other GVT members.

Employees of GVT members often feel less visible and important to the organization. The organization is also less visible to them and thus GVT members require this sort of cooperative culture. Even more than individuals who are physically located in the organization itself. It is important for GVTs to know that there's that support out there, as they need to be more encouraged due to the job demands that come from being in a GVT (vs. face-to-face team). 
Paradoxically, that support would be less visible to them and is more distant, so there needs to be more of it, or more effort needs to be made to make it more visible to the GVT member.

Proposition 3: A supportive international corporate culture is likely to function as job resource for GVTs that weakens dysfunctional effects of GVT characteristics on job demands and employee well-being.

\section{International Human Resource Management Policy}

IHRM should develop explicit organizational policies around GVT-work. It is in particular important to develop organizational guidelines for GVTs about compensation as well as about right and representation, which have been identified as pre-conditions for employee well-being (Grote \& Guest, 2016; Walton, 1976). These factors are often unclear in GVTs and strengthen existing job demands, uncertainty, and categorization processes inside the teams.

\section{International Reward System}

As GVT members often belong to a traditional team in their organization, it is important that IHRM takes care that they are explicitly rewarded for their work in the GVT based on their contribution, effort, and performance. Otherwise, they will neglect their GVT-work and a risk of social loafing may emerge. Non-committed team members are likely to strengthen negative effects of structural dynamism in GVTs, and consequently free-riding and non-commitment may spread across the team (Gino, Ayal, \& Ariely, 2009), so that nobody feels responsible for the tasks and goals in the GVT. As a result, structural dynamism's negative effects become more detrimental and members suffer from more job demands. Freeriding and non-commitment may also strengthen the divide between in- and out-groups, therefore strengthening dysfunctional effects of cultural diversity and geographic dispersion in GVTs.

GVT members should also know what is expected from them and how their performance is evaluated. IHRM should communicate performance criteria in a transparent way. GVTs are 
often composed of members who work in different countries with different economic conditions and standards. Salary differences may exist between team members due to their country of origin. In this case, IHRM should either adapt the lower salaries of the members or explain in an accurate and honest way why these differences exist. If not, jealousy and conflict may emerge (Toh \& DeNisi, 2003). This would further strengthen negative effects of cultural diversity and geographic dispersion. Adapting the salaries of GVT members from countries with lower economic conditions has to be done carefully in order to avoid perceived distributive injustice for co-workers working in the same domestic workplace. A possibility might be to reward GVT members through an extra bonus for their work in the GVT. This would satisfy GVT members and avoid negative reactions of co-workers from the domestic workplace.

\section{Rights and Representation}

Policies and legislation about rights and representation of GVT members are further important job resources for employee well-being that can be influenced by IHRM. As GVT members often belong to different teams simultaneously, it is important that HRM communicates the rights of GVT members. Employees often lack experience with GVTs, so that organizational guidelines may facilitate the teamwork of GVTs. Knowing their rights, GVT members are less likely to be distracted from their work, enabling them to focus on their actual tasks and goals. The clear communication of rights should dampen uncertainty-related problems in GVTs.

GVTs members come from different countries and subsidiaries, triggering the question of adequate representation of all members. To guarantee an adequate representation of all GVT members, it is important that all members can express their opinion, interests, and problems. It is often the case that only GVT members who work in the head office are well represented and protected regarding team decisions. However, members of subsidiaries are usually less well presented or visible, and therefore their problems and interests are neglected by the GVT as a 
whole, subsequently decreasing fairness perceptions regarding procedures and distribution of rewards. It is in this situation that IHRM needs to intervene to guarantee equal representation of all GVT members. Additionally, when used at an adequate frequency with appropriate technology choices and communication norms in the team, aspects of computer-mediated communication can increase employee voice, allowing members to be more visible and heard on a more equal level, which should increase perceptions of equal representation in these teams.

\section{Job Description}

Members of GVTs are working under different supervisors and HRM systems. Additionally, GVTs often lack clear structure and role clarity, creating uncertainty. According to uncertainty management theory (Lind \& van den Bos, 2002), employees can reduce uncertainty in their environment by relying on fair organizational procedures, systems, and structures. To reduce uncertainty and job demands in GVTs, IHRM should provide a clear and fair job description to all team members and an appropriate performance management system. This may include information about scheduling/availability, communication, performance expectations, or face-to-face meetings. These factors are potential key job resources to organize and regulate the GVT functioning (Gilson et al., 2015; Martins \& Schilpzand, 2011). It is, for example, important to analyze if the tasks, responsibilities, and work expectations are clearly communicated to GVT members. To further reduce work-related uncertainty, HRM should set clear goals, give performance feedback, show cultural sensitivity, define clear performance management processes, and establish and maintain communication (Martins \& Schilpzand, 2011). This should help GVT members to further dampen their uncertainty-related concerns and coordination problems, enabling them to concentrate on their work and manage their job demands.

Proposition 4: Clear and transparent international HRM policies are likely to function as a job resource for GVTs that weakens dysfunctional effects of GVT characteristics on job 
demands and employee well-being.

\section{International Work Environment}

\section{Flexible Work Practices and Scheduling}

Working in a GVT often affects negatively one’s work-life balance (Ruppel, Gong, \& Tworoger, 2013). For example, some members may work on a different continent with a different time zone (Nurmi, 2011). This may interfere with the personal lives of some members who have to schedule video conferences or phone calls in the night or early morning to allow all members to participate in these meetings. These unusual work hours might be experienced as stressful and demanding, boosting negative effects on employee well-being in GVTs. In addition, this may create work-family conflict for some GVT members. Work-family conflict consumes cognitive resources, which are then missing to accurately complete one's tasks or to focus on one's work (Nohe, Michel, \& Sonntag, 2014). As a consequence, some GVT members may have increased difficulties to cope with the job demands in their GVTs. Their general well-being is likely to suffer.

To avoid this vicious cycle of increased job demands and stress, it is important that IHRM takes into account the work-life balance of GVT members. This can be done through job resources such as flexible workplace practices or through communicating the expected availability of the members. Do they need to attend video conferences or phone calls at unusual work hours? Is an immediate response to emails expected? Do GVT members need to be available the whole day? These are crucial questions with regard to the work-life balance of GVT members. By providing clear and employee-friendly policies and guidelines with regard to these issues, IHRM is able to intervene in the functioning of GVTs, enabling the members to avoid work-family conflict and to concentrate on their work. They will have enough cognitive resources to cope with the stressful environment in their GVT. 


\section{Team Structure}

As GVT members operate in a stressful context, it is important that IHRM tries to develop a safe and healthy work environment. In the specific context of GVTs, IHRM may adapt the team or even organizational structure to create a safe and healthy environment. As GVTs rely on information and communication technology and are composed of members with different nationalities, uncertainty exists in GVTs with regard to interpersonal interactions, communication, and cooperation (Crisp \& Jarvenpaa, 2013). Misunderstandings and disagreements based on cultural differences occur regularly in GVTs (Kankanhalli et al., 2007). For example, some members might have an individualism orientation, whereas other members might have a collectivism orientation. Individualistic employees tend to prefer individualistic working methods as well as formal communication and relationships (Hofstede et al., 2010). In contrast, collectivistic employees tend to prefer team-based working methods and value a good relationship to their in-group. Different expectations about interpersonal interactions, decisionmaking, and communication are the consequence, creating uncertainty and unpredictability.

Structure, direction, and clarity are therefore more important in GVTs than in traditional teams. Through a clear structure, IHRM may help GVTs to reduce many misunderstandings. An effective team structure can be evaluated based on the dimensions specialization, hierarchy, and formalization (Bunderson \& Boumgarden, 2010). First, a clear and effective team structure, which provides information about the job specialization of the GVT members, is likely to improve team processes such as knowledge exchange and team learning. GVT members will know which team member they have to ask in order to get specific task-related knowledge or expertise. Second, formalizing tasks should also reduce uncertainty, misunderstandings, and disagreements, helping GVTs to develop a better team atmosphere. Despite different work expectations due to cultural differences, interpersonal interactions in GVTs are likely to become 
more predictable (Bunderson \& Boumgarden, 2010). Third, a clear hierarchy may improve team atmosphere. Clear roles and responsibilities help GVT members to understand who should do

what. This should reduce conflict. Without a clear hierarchy, GVT members may challenge each other through conflict, as a lack of decision-making power exists. This power vacuum may open the door for political games. GVT members may try to influence each other in order to protect their self-interests. This is likely to hinder these teams to benefit from their cultural diversity.

\section{Task-technology Fit}

We added the category task-technology fit, as previous research on GVTs has proposed that technology might be a key contextual factor to explain the successful functioning of GVTs (Gilson et al., 2015; Martins \& Schilpzand, 2011). The right technology infrastructure should function as a job resource that helps GVT members and facilitate their work. Conversely, the wrong technology infrastructure can complicate the work of GVTs and interfere with their functioning. How can IHRM develop the right technology infrastructure for GVTs? Generally speaking, the technology infrastructure should fit well with the team's tasks and characteristics.

Based on the consideration of information richness and social presence theory, IHRM should distinguish between synchronous (e.g., telephone and videoconferencing) and asynchronous communication tools (e.g., email and fax), and consider the information richness of communication tools (Higa, Sheng, Shin, \& Figueredo, 2000). Information richness theory (also called media richness theory) describes the information richness of communication media (Daft \& Lengel, 1986). Information richness is 'the ability of information to change understanding within a time interval' (Daft \& Lengel, 1986: 560). Social presence theory deals with the perceived social awareness of the communication partner in the communication (Short, Williams, \& Christie, 1976). Intimacy and immediacy of the communication are important predictors of perceived social awareness (Burgoon, Buller, Hale, \& deTurck, 1984). 
The distinction between synchronous and asynchronous tools can help IHRM to create an effective technology infrastructure for GVTs. Synchronous communication occurs in real time, whereas asynchronous communication occurs at different time points. Information richness include communication categories such as channel type (e.g., video and email), language (e.g., natural, body, and numeric), and communication type (formal vs. informal) (Daft \& Lengel, 1984; Peltokorpi, 2014). The choice of the right communication tools depends on the type of the tasks. Complex and interdependent tasks rather require synchronous and socially rich tools (e.g., video). This allows team members to exchange and discuss in real time. Asynchronous and less socially rich tools (e.g., email) are sufficient for independent and complementary tasks. This facilitates team members' concentration on their tasks and the communication of their outcomes to their teammates. The right matching between communication tools and tasks is likely to help GVT members to cope with stressful situations in their team and to appropriately manage cultural differences and electronic dependence (Peltokorpi, 2014).

HRM should help GVT members to select the right technologies for their tasks in order to reduce job demands in GVTs that result from cultural diversity, geographic dispersion, and electronic dependence. This would help GVTs to weaken negative effects on coordination and communication in GVTs (Massey, Hung, Montoya-Weiss, \& Ramesh, 2001), improving employee well-being. In particular, collaboration software, meeting software, and document sharing are likely to compensate dysfunctional effects of cultural diversity, structural dynamism, and geographic dispersion on knowledge exchanges and team learning. Through these tools, it will be easier for GVT members to share their different perspectives and knowledge with teammates. GVTs are composed of members with different expertise, knowledge, and experiences, creating the basis of knowledge exchange and team learning. However, these differences also need to be communicated and exchanged in order to create benefits for team 
performance.

Additionally, IHRM should consider the geographic dispersion of the GVT members. If members work in different time zones, it is important to provide asynchronous communication technology. If members work in the same or similar time zone, synchronous communication technology might be the preferred option to facilitate learning as well as knowledge and information exchanges. The right technology infrastructure therefore allows GVT members to better cope with geographic dispersion in their teams and to dampen related job demands.

Proposition 5: A flexible and employee-friendly environment is likely to function as a job resource for GVTs that weakens dysfunctional effects of GVT characteristics on job demands and employee well-being.

\section{Discussion}

A new way of organizing work is the implementation of GVTs. International organizations need to incorporate this new type of organizing work in order to develop effective IHRM practices. For this purpose, we introduced a new employee-focused IHRM perspective for the management of GVTs. One main contribution of this article is the integration of the literatures of GVTs and HRM. Although GVTs are important success factors for international organizations, we do not know much about the successful management of these teams. Previous research has mostly focused on the situation inside the team, neglecting the role of leaders (Zander et al., 2012) and HRM for GVTs (Gilson et al., 2015; Martins \& Schilpzand, 2011). By drawing on the JDR model (Demerouti et al., 2001) and research on quality of work life (Walton, 1976), we introduced several employee-focused IHRM tools that may help IHRM to build an inclusive international work environment that weakens negative effects of GVT characteristics (cultural diversity, electronic dependence, geographic dispersion, and structural dynamism) on employee well-being. We classified several job resources in four overall categories: 1) 
Development of international skills and careers, 2) international corporate culture, 3) IHRM policies, and 4) work-life balance.

The first category focuses on the development and growth of employees. We explained several international-oriented HR training programs that are likely to function as job resources for GVT members. In addition, GVT-work must be clearly integrated in the career development culture of the organization (Dickmann \& Haris, 2005). A successful implementation of these tools will allow GVT members to cope more effectively with job demands. The second category deals with the social side in the workplace. HRM should not only help GVTs to develop social cohesion but it should also communicate the purpose and goals of the team. It is important for employees to know that their work is meaningful and why and how their work contributes to the overall success of the organization (Steger, Dik, \& Duffy, 2012). Due to their cultural diversity and geographic dispersion, it is further important that GVTs experience a fair work environment based on equal treatment and respect. Otherwise, social categorization processes based on cultural diversity are likely to be strengthened, increasing job demands and reducing well-being. A supportive corporate culture should also include non-GVT members, who should be cooperative and sympathetic toward GVT members and their additional workload and responsibilities. The third category deals with the formal management of GVTs such as compensation, rights and representation, and job description. Generally, it is beneficial if IHRM provides clear policies and guidelines to GVTs in order to reduce uncertainty in this stressful and complex environment. This will free up cognitive resources for GVT members that they can use to manage successfully job demands in the GVT. The final category explicitly focuses on the work-life balance of GVT members. Due to time differences and stressful interactions, it is important that IHRM provides GVT members with flexible work schedules and with appropriate technology to manage their interactions with teammates. 
We expand GVT research by taking a new well-being perspective to improve the work experience of GVT members. Research on GVTs has identified several important key factors in GVTs with regard to task performance (Gilson et al., 2015), but it did not take into account the well-being of the team members (Martins \& Schilpzand, 2011). This means GVT research often took an instrumental perspective to investigate team functioning. GVT members often have to cope with stressful job demands that impair with their well-being. Examples are interpersonal conflict, electronic communication, working in a stressful environment with time differences, cultural differences, and dysfunctional team dynamics (Furoma, 2009). To cope with these demands, we provided several employee-focused management tools that HR managers can apply to improve the well-being of GVT members.

By focusing on employee well-being as key outcome, we also advance HRM research. Previous HRM research has tended to focus on employee productivity and financial performance (Beer et al., 2015; Guest, 2011). Even when research included employee well-being, commitment, and engagement, it considered these employee-oriented variables rather as means to increase employee productivity and financial performance (Guest, 2011). Based on the JDR model (Demerouti et al., 2001) and research on the quality of work life (Walton, 1976), we introduced an employee-focused HRM perspective in order to better understand the functioning of GVTs, to improve employee well-being, and to improve the management of GVTs. An employee-focused HRM perspective focuses as primary goal on the well-being of employees (Guest \& Woodrow, 2011). The application of employee-focused HRM tools is likely to help GVT members to reduce or even prevent job demands in GVTs. Employee-focused HRM tools can be considered as job resources that function as a source of energy, freeing up cognitive resources for GVT members, or helping members to cope with existing job demands. Employeefocused HRM is based on pre-conditions that guarantee employee well-being. As a result, 
employees are likely to feel less stressed and more satisfied, as they are more capable to deal with daily job demands. The organization is also likely to benefit from the application of an employeefocused HRM perspective, because employee commitment and engagement are likely to increase in the long-term. One reason why an employee-focused perspective has not been investigated by previous HRM is that such perspective could not be very popular among practitioners due to the current short-term focus in most organizations. Many organizations strive for short-term benefits, while employee-focused approaches promise rather long-term benefits. It is often more important for managers to increase employee productivity in the short term than to increase employee wellbeing in the long term.

Finally, we also contribute to research on the JDR model (Bakker \& Demerouti, 2007; Demerouti et al., 2001) by applying it to the context of GVTs. The model is based on an imbalance of job demands and job resources. Accordingly, we first identified the specific job demands in the context of GVTs such as interpersonal conflict, perceptions of injustice, reduced trust and identification, dysfunctional knowledge exchanges, and reduced learning. These GVT job demands are likely to elicit health impairment processes that negatively influence well-being of GVT members. To dampen these job demands, we introduced several job resources that can be used by HRM. We call these job resources employee-focused HRM tools. These tools are able to bridge the interpersonal differences in GVTs and to help their members to manage their stressful interactions and environment. Taken together, we illustrate the JDR model is a useful theoretical lens to understand GVTs and to improve the well-being of their members.

\section{Practical Implications}

Previous research has reported that leading and working in GVTs represent an enormous challenge for most leaders and employees (Zander \& Butler, 2010; Zander et al., 2012). We developed a practitioner-oriented framework that can serve as a starting point to guide $\mathrm{HR}$ 
managers, GVT leaders and members, and scholars to identify tools to improve well-being and functioning in GVTs. GVTs have a high performance potential resulting from their cultural diversity and variety of perspectives. Cultural diversity includes, for example, different cultural backgrounds, experiences, and perspectives (Gibson \& Gibbs, 2006). This can improve decisionmaking and stimulate knowledge exchanges. However the potential is often not exploited due to different expectations and dysfunctional conflict. It is therefore important for IHRM to assist GVTs and to help these teams to strengthen the positive effects of cultural diversity and to weaken the negative effects. Our theoretical framework offers HR managers and team leaders several management tools to help GVTs to transform their potential into well-being and performance. Our analysis of GVTs further offers new insights into the relations between different aspects of team members' work experience and different international HR practices.

In this article, we used French-German teams from Airbus as example to illustrate possible job demands in GVTs. It is noteworthy that the top management and HRM of Airbus took right measures to avoid similar problems in the future (RegionsJob, 2013). For example, they aim to develop a truly international corporate culture in which cultural differences are not neglected but considered a valuable source for creativity and innovation (Airbus, 2017). To develop this culture, they introduced English as main language in the workplace (although most employees are French and German), allowing a better social integration of all employees independently of their nationality (The Local, 2014). In addition, Airbus offers international work assignments to their employees and regularly measures the work engagement and commitment of its employees. Airbus also adapted the salaries to avoid large salary differences between employees from different nations or between expatriates and the native workforce.

\section{Strengths, Limitations, and Future Research}

One strength of our framework is that it takes into account HRM context by considering 
the roles of organizational development initiatives, organizational culture, HRM policies, technology infrastructure, and work environment. In this way, it acknowledges that GVTs are nested in organizations and their cultures, and that GVT dynamics can be influenced by the broader organizational and societal context. It pays attention to the influence of the HRM context on employee attitudes and behaviors, advancing the general integration of HRM research and organizational behavior research (Guest, 2004). Another strength of our employee-focused HRM perspective and the related framework is its theoretical foundation based on the JDR model.

There are also several avenues for future research. Some scholars and practitioners may like to receive more information on improving financial performance. It is noteworthy that our focus on employee well-being does not interfere with financial performance. Well-being is directly related to work engagement, which predicts performance (Shimazu, Schaufeli, Kamiyama, \& Kawakami, 2015). Well-being also relates to organizational commitment. Committed employees identify with their organization and are less likely to quit their job. This will create long-term benefits, because the organization will save financial costs in recruitment and be able to develop their employees to future leaders who know very well their organization.

The propositions of this framework remain subject to empirical testing. Due to the complexity of our framework, we recommend testing our framework in several steps. Scholars should apply multilevel methods and longitudinal designs. Multilevel approaches are necessary to capture the influence of HRM and leaders on individual employee well-being and interactions inside the team. Longitudinal designs are also necessary, as GVT-work is dynamic and effects of job demands and job resources require some time to unfold. For example, over a short time period, GVT members might be able to manage their job demands. However, over a longer time period, it is likely to become too demanding to manage job demands and stressful interactions inside GVTs. Stress, reduced well-being, and even burn-out could be the consequences. 


\section{References}

Airbus (2017). People \& Culture. http://www.airbus.com/company/people-culture/ (03/02/2017).

Au, Y., \& Marks, A. (2012). Virtual teams are literally and metaphorically invisible: Forging identity in culturally diverse virtual teams. Employee Relations, 34, 271-287.

Bakker, A. B., \& Demerouti, E. (2007). The job demands-resources model: State of the art. Journal of Managerial Psychology, 22, 309-328.

Becker, B. E., \& Huselid, M. A. (1998). High performance work systems and firm performance: A synthesis of research and managerial implications. Research in Personnel and Human Resource Management, 16, 53-101.

Beer, M., Spector, B., Lawrence, P. R., Quinn Mills, D., \& Walton, R. E. (1984). Managing Human Assets. New York, NY: The Free Press.

Beer, M., Boselie, P., \& Brewster, C. (2015). Back to the Future: Implications for the Field of HRM of the Multistakeholder Perspective Proposed 30 Years Ago. Human Resource Management, 54(3), 427-438. doi: 10.1002/hrm.21726

Bertolotti, F., Mattarelli E., Vignoli M., \& Macrì, D. M. (2015). Exploring the relationship between multiple team membership and performance: the role of social networks and collaborative technologies, Research Policy, 44, 911-924

Biemann, T., \& Andresen, M. (2010). Self-initiated foreign expatriates versus assigned expatriates: Two distinct types of international careers? Journal of Managerial Psychology, 25, 430-448.

Blackburn, R., Furst, S., \& Rosen, B. (2003). Building a winning virtual team, in Gibson, C. and Cohen, E.G. (Eds), Virtual Teams that Work: Creating Conditions for Virtual Team Effectiveness, 95-120, Jossey Bass, San Francisco, CA.

Bluedorn, A. C., Kaufman, C. J., \& Lane, P. M. (1992). How many things do you like to do at once? An introduction to monochronic and polychronic time. The Academy of Management Executive, 6, 17-26.

Boxall, P., \& Macky, K. (2009). Research and theory on high-performance work systems: progressing the high-involvement stream. Human Resource Management Journal, 19, 3-23.

Brown, S., McHardy, J., McNabb, R., \& Taylor, K. (2011). Workplace performance, worker commitment, and loyalty. Journal of Economics \& Management Strategy, 20, 925-955.

Bunderson, S., \& Boumgarden, P. (2010). Structure and learning in self-managed teams: Why "bureaucratic" teams can be better learners. Organization Science, 21, 609-623.

Burgoon, J. K., Buller, D.B., Hale, J. L., \& deTurck, M. A. (1984). Relational messages associated with nonverbal behaviors. Human Communication Research, 10, 351-378. 
Cogburn, D. L., Zhang, L., \& Khothule, M. (2002). Going global, locally: The Socio-technical influences on performance in distributed collaborative learning teams. Proceedings of SAICSIT, 52-64.

Cohen, S. G., \& Gibson, C. B. (2003). In the beginning: Introduction and framework. In C. B. Gibson \& S. G. Cohen (Eds.), Virtual teams that work: Creating conditions for virtual team effectiveness: 1-13. San Francisco: Jossey-Bass.

Collins, N., Chou, Y. M., Warner, M., \& Rowley, C., (2015). Human factors in East Asian virtual teamwork: a comparative study of Indonesia, Taiwan and Vietnam. The International Journal of Human Resource Management, 1-24.

Crisp, C. B., \& Jarvenpaa, S. L. (2013). Swift Trust in Global Virtual Teams. Journal of Personnel Psychology, 12, 45-56.

Daft, R. L., \& Lengel, R. H. (1984). Information richness: A new approach to managerial behavior and organizational design. In: B. M. Staw \& L. L. Cummings (Eds), Research in organizational behaviour, 191-233). Greenwich, CT: JAI Press.

Daft, R. L., \& Lengel, R. J. (1986). Organizational information requirements, media richness and structural design. Management Science, 32, 554-571.

Daim, T. U., Reutiman, H. A., Hughes, S., Pathak, B., Bynum, U. W., \& Bhatla, A. (2012). Exploring the communication breakdown in global virtual teams. International Journal of Project Management, 30, 199-212.

Demerouti, E., Bakker, A. B., \& Leiter, M. (2014). Burnout and job performance: The moderating role of selection, optimization, and compensation strategies. Journal of Occupational Health Psychology, 19, 96-107.

Demerouti, E., Bakker, A. B., Nachreiner, F., \& Schaufeli, W. B. (2001). The job demandsresources model of burnout. Journal of Applied Psychology, 86, 499-512

Deutsch, M. (2002). Social psychology's contributions to the study of conflict resolution. Negotiation Journal, 307-320.

Dickmann, M., \& Doherty, N. (2008). Exploring the career capital impact of international assignments within distinct organizational contexts. British Journal of Management, 19, 145161.

Dickmann, M., \& Harris, H. (2005). Developing career capital for global careers: The role of international assignments. Journal of World Business, 40, 399-408.

Dowling P. J., Festing, M., \& Engle, A. D. (2008). International human resource management: Managing people in a multinational context (5th ed.). London: Cengage Learning.

Earley, P. C., Gibson, C. B. (2002). Multinational work teams: A new perspective. Mahwah, NJ: Lawrence Erlbaum Associates. 
Erez, M., Lisak, A., Harush, R., Glikson, E., Nour, R., \& Shokef, E. (2013). Going global: developing management students' cultural intelligence and global identity in virtual culturally diverse teams. Academy of Management Learning and Education, 12, 330-55.

Furumo, K. (2009). The impact of conflict and conflict management style on deadbeats and deserters in virtual teams. Journal of Computer Information Systems, 49, 66-73.

Gibbs, J. L., \& Boyraz, M. (2015). 'IHRM's Role in Managing Global Teams'. In D.G.Collings, G.T. Wood, \& P.M. Caligiuri (Eds.) The Routlege Companion to International Human Resource Management, New York: Routledge, 552-551.

Gibson, C. B., \& Gibbs, J. L. (2006). Unpacking the Concept of Virtuality: The Effects of Geographic Dispersion, Electronic Dependence, Dynamic Structure, and National Diversity on Team Innovation. Administrative Science Quarterly, 451-495.

Gibson, C., \& Manuel, J. A. (2003). Building trust: Effective multicultural communication processes in virtual teams. In C. Gibson \& S.G. Cohen (Eds.), Virtual teams that work: creating conditions for virtual team effectiveness, 59-86. San Francisco: Jossey-Bass.

Gilson, L. L., Maynard, M. T., Jones Young, N., Vartiainen, M., \& Hakonen, M. (2015). Virtual teams research: Ten years, ten themes, and ten opportunities. Journal of Management, doi: $10.1177 / 0149206314559946$.

Gino, F., Ayal, S., \& Ariely, D. (2009). Contagion and differentiation in unethical behavior: The effect of one bad apple on the barrel. Psychological Science, 20, 393-398.

Goleman, D. (2009). Ecological intelligence. New York: Crown

Gupta, A. K. \& Govindarajan, V. (2002). Cultivating a global mindset. Academy of Management Executive, 16, 116-126.

Greenwood, M., \& De Cieri, H. (2007). Stakeholder theory and the ethics of HRM. In A. Pinnington, R. Macklın, \& T. Campbell (Eds.), Human resource management: Ethics and employment (pp. 119-136). New York: Oxford University Press.

Grote, G., \& Guest, D. (2016). The case for reinvigorating quality of working life research. Human Relations, 70, 149-167.

Guest, D. (2004). Flexible employment contracts, the psychological contract and employee outcomes: an analysis and review of the evidence. International Journal of Management Reviews, 5/6, 1-19.

Guest, D. E. (2011). Human resource management and performance: still searching for some answers. Human Resource Management Journal, 21, 3-13.

Guest, D., \& Woodrow, C. (2012). Exploring the Boundaries of Human Resource Managers' Responsibilities. Journal of Business Ethics, 111, 109-119. 
Higa, K., Sheng, O. R. L., Shin, B., \& Figueredo, A. J. (2000). Understanding relationships among teleworkers' e-mail usage, e-mail richness perceptions, and e-mail productivity perceptions under a software engineering environment. IEEE Transactions on Engineering Management, 47, 163-173.

Hinds, P., \& Weisband, S. P. (2003). Knowledge sharing and shared understanding in virtual teams. In C. B. Gibson \& S. G. Cohen (Eds.), Virtual teams that work: creating conditions for virtual team effectiveness: 21-36. San Francisco, CA: Jossey-Bass.

Hofstede, G., Hofstede, G. J. \& Minkov, M. (2010). Cultures and Organizations: Software of the Mind (Rev. 3rd ed.). New York: McGraw-Hill.

Hogg, M. A., \& Terry, D. J. (2000). Social identity and self-categorization processes in organizational contexts. Academy of Management Review, 121-140.

Kankanhalli, A., Tan, B. C. Y., \& Wei, K-K. (2007). Conflict and performance in global virtual teams. Journal of Management Information Systems, 23, 237-274.

Kurland, N. B. \& Bailey, D. E. (1999). Telework: The advantages and challenges of working here, there, anywhere, and anytime. Organizational Dynamics, 28, 53-68.

L'express (2010). Grève chez Airbus sur fond de jalousie franco-allemande. http://lexpansion.lexpress.fr/actualite-economique/greve-chez-airbus-sur-fond-de-jalousiefranco-allemande_1376497.html (03/02/2017).

La Dépêche (2008). Airbus : le mariage franco-allemand bat de l'aile. http://www.ladepeche.fr/article/2008/06/20/460432-airbus-le-mariage-franco-allemand-batde-l-aile.html (03/02/2017).

Le Monde (2008). Louis Gallois tente d'apaiser les tensions franco-allemandes chez Airbus. http://www.lemonde.fr/economie/article/2008/05/30/louis-gallois-tente-d-apaiser-lestensions-franco-allemandes-chez-airbus_1051603_3234.html (03/02/2017).

Li, A., \& Cropanzano, R. (2009). Fairness at the group level: Justice climate and intraunit justice climate. Journal of Management, 564-599.

Lind, E. A., \& van den Bos, K. (2002). When fairness works: Towards a general theory of uncertainty management. In B. M. Straw \& R. M. Kramer (Eds.) Research in organizational behavior, 181-223. Boston: Elsevier.

Lipnack, J., \& Stamps, J. (1999). Virtual teams. Executive Excellence, 16, 14-15.

Marks, M., Mathieu, J., \& Zaccaro, S. (2001). A temporally-based framework and taxonomy of team processes. Academy of Management Review, 530-547.

Martins, L. L., \& Shalley, C. E. (2011). Creativity in virtual work: Effects of demographic differences. Small Group Research, 42, 536-561. 
Martins, L. L., \& Schilpzand, M. C. (2011). Global virtual teams: Key developments, research gaps, and future directions. Research in Personnel and Human Resources Management, 30, 1-72.

Massey, A. P., Hung, C., Montoya-Weiss, M. M., \& Ramesh, V. (2001). When culture and style aren't about clothes: Perceptions of task-technology "fit'" in global virtual teams. Group, September 30-October 3, Boulder, CO.

Maynard, M. T., Mathieu, J. E., Rapp, T. L., \& Gilson, L. L. (2012). Something(s) old and something(s) new: Modeling drivers of global virtual team effectiveness. Journal of Organizational Behavior, 33, 342-365.

Molines, M., Sanséau, P.-Y., \& Adamovic, M. (2017). How organizational stressors affect collective organizational citizenship behaviors in the French Police: The moderating role of trust climate. International Journal of Public Sector Management, 30, 48-66.

Montoya, M. M., Massey, A. P., \& Lockwood, N. S. (2011). 3D collaborative virtual environments: Exploring the link between collaborative behaviors and team performance. Decision Sciences, 42, 451-476.

Newell, S., David, G., \& Chand, D. (2007). An analysis of trust among globally distributed work teams in an organizational setting. Knowledge \& Process Management, 14, 158-168.

Nishii, L. H., \& Özbilgin, M. F. (2007). Global diversity management: Towards a conceptual framework. International Journal of Human Resource Management, 18, 1883-1894

Nohe, C., Michel, A., \& Sonntag, K. (2014). Family-work conflict and job performance: A diary study of boundary conditions and mechanisms. Journal of Organizational Behavior, 35, 339357.

Nurmi, N. (2011). Coping with coping strategies: How distributed teams and their members deal with the stress of distance, time zones and culture. Stress and Health, 27, 123-143.

Okpara, J. O., \& Kabongo, J. D. (2010). Corporate governance in a developing economy: A study of barriers and issues in Nigeria. SAM Advanced Management Journal, 75, 41-52.

Oncomprendrhin (2011). Coopération franco-allemande et incidents interculturels. https://oncomprendrhin.wordpress.com/2014/11/11/cooperation-franco-allemandemanagement $(03 / 02 / 2017)$.

Peltokorpi, V. (2014). Corporate Language Proficiency and Reverse Knowledge Transfer in Multinational Corporations: Interactive Effects of Communication Media Richness and Commitment to Headquarters. Journal of International Management, 21, 49-62.

Polzer, J. T., Crisp, B., Jarvenpaa, S. L., \& Kim, J. W. (2006). Extending the faultline concept to geographically dispersed teams: How colocated subgroups can impair group functioning. Academy of Management Journal, 49, 679-692.

Ramalingam, S., \& Mahalingam, A. (2011). Enabling conditions for the emergence and effective 
performance of technical and cultural boundary spanners in global virtual teams. Engineering Project Organization Journal, 1, 121-41.

RegionsJob (2013). Palmarès Employeurs RegionsJob 2013.

http://groupe.regionsjob.com/media/docs/CP_PalmaresEmployeurRegionsJob2013_national. $\operatorname{pdf}(03 / 02 / 2017)$.

Reiche, B. S., \& Harzing, A. K. (2011). International assignments. In A. H. Pinnington \& A. K. Harzing (Eds.), International Human Resource Management (3rd ed., 185-226). Thousand Oaks, CA.: Sage Publications.

Rico, R., Sánchez-Manzanares, M., Gil, F. \& Gibson, C. (2008). Team Implicit Coordination Processes: A Team Knowledge-Based Approach. Academy of Management Review, 33, $163-$ 184.

Ruppel, C. P., Gong, B., \& Tworoger, L. C. (2013). Using communication choices as a boundary management strategy: How choices of communication media affect the work-life balance of teleworkers in a global virtual team. Journal of Business and Technical Communication, 27, 436-471.

Schaufeli, W. B. (2015). Engaging leadership in the job demands-resources model. Career Development International, 20, 446-463.

Schneider, B., (1990). The climate for service: An application of the climate construct. In B. Schneider (Ed.), Organizational climate and culture, 383-412. San Francisco: Jossey-Bass.

Shimazu, A., Schaufeli, W. B., Kamiyama, K. \& Kawakami, N. (2015). Workaholism vs. Work Engagement: the Two Different Predictors of Future Well-being and Performance. International Journal of Behavioral Medicine, 22, 18-23.

Short, J., Williams, E., \& Christie, B. (1976). The social psychology of telecommunications. London. John Wiley \& Sons, Ltd.

Stahl, G. K., \& Cerdin, J.-L. (2004). Global careers in French and German multinational corporations. Journal of Management Development, 23, 885-902.

Stahl, G. K., Miller, E. L., \& Tung, R. L. (2002). Toward the boundaryless career: A closer look at the expatriate career concept and the perceived implications of an international assignment. Journal of World Business, 37, 216-227.

Stark, E. M., \& Bierly, P. E. III. (2009). An analysis of predictors of team satisfaction in product development teams with differing levels of virtualness. $R \& D$ Management, 39, 461-472.

Steger, M. F., Dik, B. J., \& Duffy, R. D. (2012). Measuring meaningful work: The Work and Meaning Inventory (WAMI). Journal of Career Assessment, 20, 322-337.

Stone, D., \& Dulebohn, J. (2013). Emerging issues in theory and research on electronic human resource management (eHRM). Human Resource Management Review, 23, 1-5. 
Stone-Romero, E. F., \& Stone, D. L. (2005). How do organizational justice concepts relate to discrimination and prejudice. In J. Greenberg \& J. A. Colquitt (Eds.), Handbook of organizational justice, 439-467. Mahwah, NJ: Lawrence Erlbaum Associates Publishers.

Sy, T., Cote S., \& Saavedra, R. (2005). The contagious leader: Impact of the leader's mood on the mood of group members, group affective climate, and group processes. Journal of Applied Psychology, 90, 295-305.

Taras, V., Kirkman, B. L., \& Steel, P. (2010). Examining the impact of culture's consecuences: A three-decade, multilevel, meta-analytic review of Hofstede's cultural value dimensions. Journal of Applied Psychology, 95, 405-439.

The Local (2014). Airbus chief: 'I no longer think like a Frenchman'. http://www.thelocal.fr/20140320/france-needs-to-love-its-companies (03/02/2017).

Tims, M., Bakker, A. B., \& Xanthopoulou, D. (2011). Do transformational leader enhance their followers' daily work engagement? The Leadership Quarterly, 22, 121-131.

Toh, S. M., \& DeNisi, A. S. (2003). Host country national (HCN) reactions to expatriate pay policies: A model and implications. Academy of Management Review, 28, 606-621.

Walton, R. E. (1976). Criteria for quality of work life. In: Davis, L. E. \& Cherns, A.B.: Quality of working life: problems, projects and the state of the art. New York: Macmillian, 91-104.

Whitener, E. M. (2001). Do "high commitment" human resource practices affect employee commitment? A cross-level analysis using hierarchical linear modeling. Journal of Management, 27, 515-535.

Whitman, D. S., Carpenter, N. C., Horner, M. T., \& Bernerth, J. B. (2012). Fairness at the collective level: A meta-analytic examination of the consequences and boundary conditions of organizational justice climate. Journal of Applied Psychology, 776-791.

Zander, L., \& Butler, C. L. (2010). Leadership modes: Success strategies for multicultural teams, Scandinavian Journal of Management, 258-267.

Zander, L., Mockaitis, A. I., \& Butler, C. L. (2012). Leading global teams. Journal of World Business, 47, 592-603. 


\section{Figure 1}

Theoretical Framework

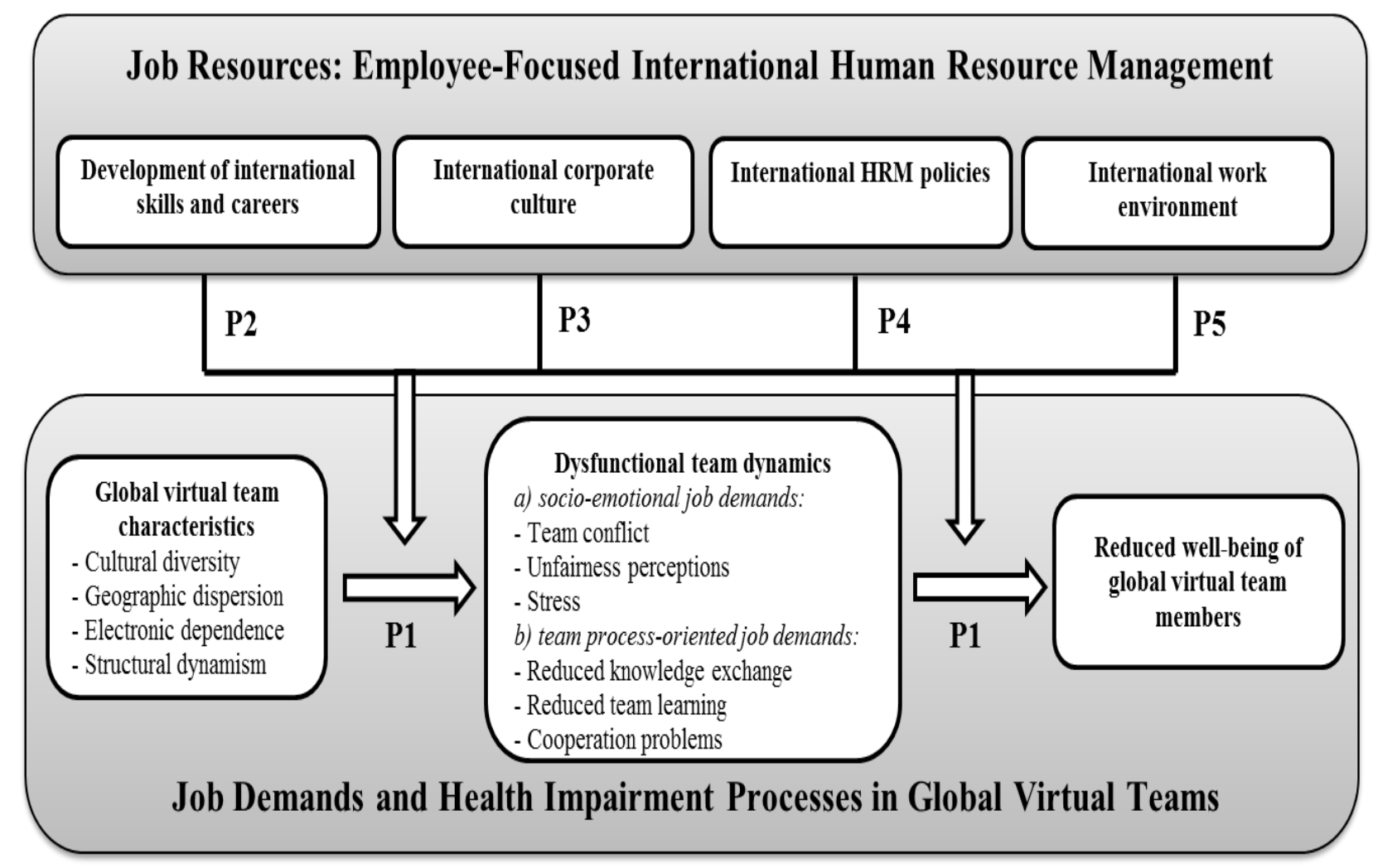

Note. To develop the theoretical framework, we drew on previous work of Demerouti and colleagues (2001) and Walton (1976). 
Figure 2

Employee-Focused Human Resource Management Tools

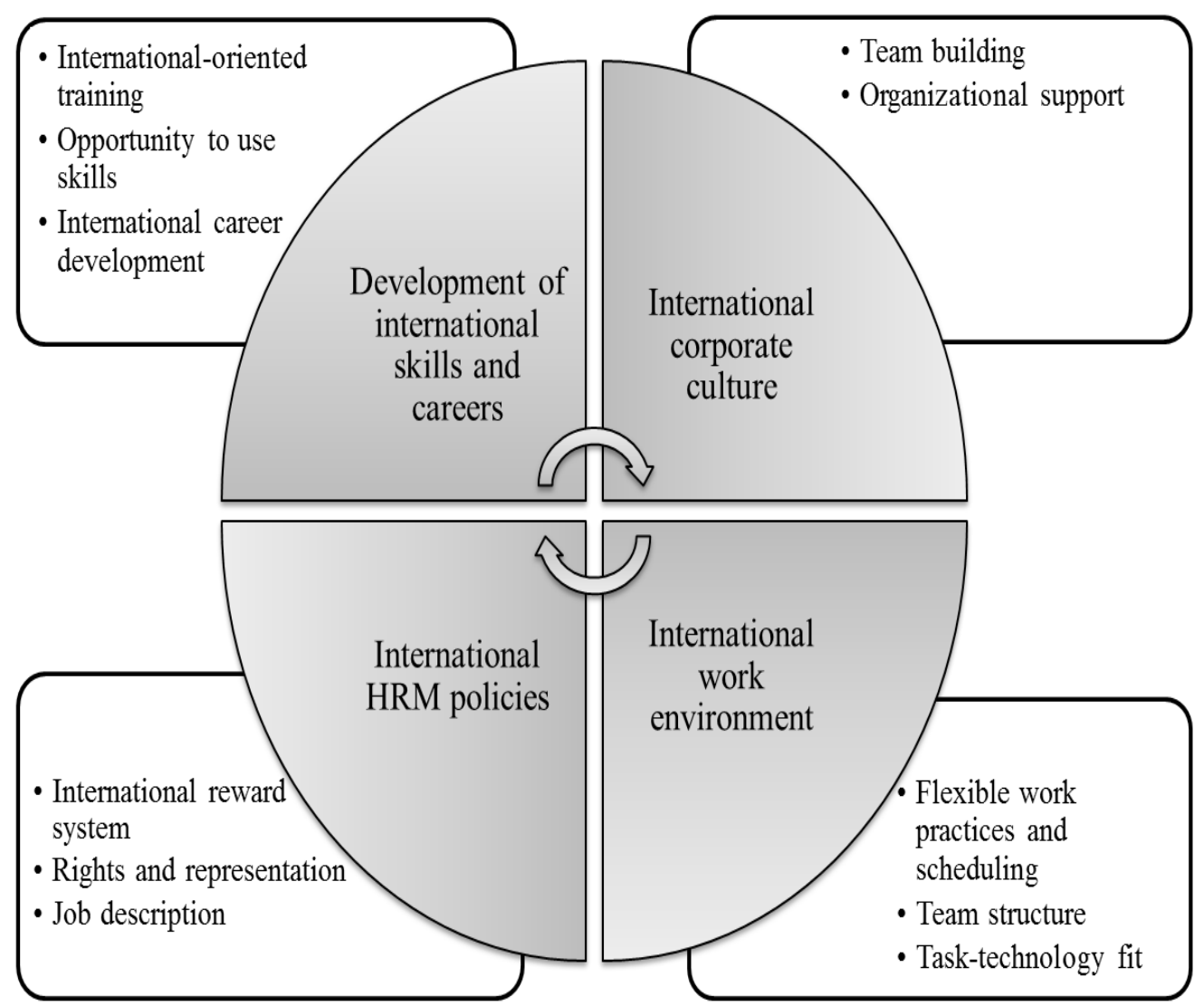

Note. To develop this classification, we drew on previous work of Walton (1976). 